\title{
Anestesia para injeção percutânea de etanol guiada por tomografia computadorizada para tratamento de feocromocitoma
}

\author{
Disciplina de Anestesiologia da Faculdade de Medicina \\ da Universidade de São Paulo, São Paulo
}

INTRODUÇÃa

O feocromocitoma apresenta incidência de 1:200.000 indivíduos e caracteriza-se clinicamente por aumento intermitente da pressão arterial, episódios de sudorese, cefaléia e palpitações, associados a aumento de catecolaminas sanguíneas e urinárias. A ressecção cirúrgica representa um tratamento curativo, porém traumático, além de apresentar risco relativamente alto e custo elevado. Portanto, alternativas inovadoras e menos invasivas de tratamento têm sido propostas, como a injeção percutânea de etanol guiada por tomografia computadorizada.

RELATI DO CASD

Paciente de 57 anos, hipertensa e diabética, apresentando lesão adrenal unilateral (esquerda) medindo $8 \mathrm{~cm}$ de diâmetro, com diagnóstico estabelecido de feocromocitoma hiperfuncionante. A paciente realizou preparo pré-anestésico com prazosin por duas semanas e recebeu midazolam $(7,5 \mathrm{mg})$ intramuscular como medicação pré-anestésica. Após venóclise em membro superior direito com cateter $14 \mathrm{G}$, foi submetida à anestesia geral com propofol, fentanil e atracúrio, e manutenção com sevoflurano. A monitorização foi realizada com cardioscópio, oximetria de pulso e pressão arterial média (PAM) invasiva contínua com cateter $20 \mathrm{G}$ em artéria radial esquerda. $\mathrm{O}$ procedimento evoluiu sem intercorrências. Durante a injeção de etanol, a paciente evoluiu com aumento súbito da PAM até $130 \mathrm{mmHg}$ e taquicardia $(140 \mathrm{bpm})$ com controle imediato após infusão de nitroprussiato de sódio (NPS) até a dose de $10 \mu \mathrm{g} / \mathrm{kg} / \mathrm{min}$. Após o procedimento, permaneceu estável hemodinamicamente, com NPS $0,5 \mu \mathrm{g} / \mathrm{kg} / \mathrm{min}$, sendo extubada sem intercorrências e encaminhada à UTI pós-operatória, onde permaneceu em observação por 24 horas.

\section{DISCUSSÃロ}

A injeção de etanol para tratamento de feocromocitoma é um procedimento novo, realizado pela primeira vez no Brasil. Apenas um artigo na literatura relata uma série de 41 casos com boa evolução, mas não discute a monitorização e os cuidados anestésicos.

CanCLUSÃ̃

Concluímos que a monitorização invasiva da pressão arterial é fundamental para bom controle pressórico durante a injeção de etanol. Maior experiência com esse procedimento ainda é necessária para determinar seu perfil de segurança.

REFERÊNCIA

Wang P, et al. Computerized tomography guided percutaneous ethanol injection for the treatment ofhyperfunctioningpheochromocytoma. J Urol. 2003;170:1132-4.

\section{Endereço para correspondência:}

Ricardo A. G. Barbosa

Rua Cardoso de Siqueira, 67 - casa 10 - Aclimação

São Paulo (SP) - CEP 01530-090

Tel. (+55 11) 9934-4765

E-mail: navajasbarbosa@ig.com.br 